\title{
Study the Chromium-Induced Oxidative Stress on Mitochondria from Liver and Lungs Origin
}

\author{
Durga Pada Dolai ${ }^{1}$, Sankar Kumar Dey ${ }^{2,}$,, Sandeep Kumar Dash ${ }^{1}$, Somenath Roy ${ }^{1}$ \\ ${ }^{1}$ Department of Human Physiology with Community Health, Vidyasagar University, Midnapore, India \\ ${ }^{2}$ Department of Physiology, S. B. S. S. Mahavidyalaya, Paschim Medinipur, India
}

\section{Email address:}

dolailaxmi@yahoo.com (D. P. Dolai), sankar_dey@yahoo.co.in (S. K. Dey), deep.vu@gmail.com (S. K. Dash), sroy.vu@mail.vidyasagar.ac.in (S. Roy)

${ }^{*}$ Corresponding author

\section{To cite this article:}

Durga Pada Dolai, Sankar Kumar Dey, Sandeep Kumar Dash, Somenath Roy. Study the Chromium-Induced Oxidative Stress on Mitochondria from Liver and Lungs Origin. American Journal of Applied Scientific Research. Vol. 2, No. 6, 2016, pp. 59-64. doi: $10.11648 /$ j.ajasr.20160206.15

Received: September 18, 2016; Accepted: October 19, 2016; Published: December 17, 2016

\begin{abstract}
Potassium dichromate $\left(\mathrm{K}_{2} \mathrm{Cr}_{2} \mathrm{O}_{7}\right)$, a $\mathrm{Cr}$ (VI) compound, is the most toxic form of $\mathrm{Cr}(\mathrm{VI})$ and has been demonstrated to induce toxicity associated with oxidative stress in humans and animals. The wide environmental distribution of chromium leads to an increased interest of its toxicity and biological effects. Mitochondria provide most of the cellular energy (ATP) and yield many intermediate compounds involved in normal cellular metabolism. Therefore, perturbations of mitochondrial function may result in severe consequences for general metabolism and all the energy transducing processes that require ATP. The present study was designed to investigate the $\mathrm{Cr}(\mathrm{VI})$-induced oxidative stress on mitochondria in liver and lungs. Male albino rats of Wistar strain $(80-100 \mathrm{~g})$ were used for the present study. Rats were divided into two groups of almost equal average body weight. The animals of one group were injected (i.p.) $\mathrm{K}_{2} \mathrm{Cr}_{2} \mathrm{O}_{7}$ at a dose of $0.8 \mathrm{mg}$ per $100 \mathrm{~g}$ body weight per day for 28 days. The animals of the remaining group received only the vehicle $(0.9 \% \mathrm{NaCl})$, served as control. Measurement of oxidative stress biomarkers like lipid peroxidation (MDA), conjugated dienes and nitric oxide contents were increased in both liver and lungs mitochondria. The decreased antioxidant marker enzymes like the activities of glutathione peroxidase (GSH-Px), glutathione reductase (GR), glutathione-S-transferase (G-S-T), superoxide dismutase (SOD) and catalase (CAT) of $\mathrm{Cr}(\mathrm{VI})$ treated rats were accompanied by a significant decrease in the level of glutathione's (GSH and GSSG) in liver and lungs mitochondria. The results of the present study demonstrates that the exposure of Cr (VI) at the present dose and duration caused reduction in LPO and antioxidant enzyme activities in rat's liver and lungs mitochondria.
\end{abstract}

Keywords: Chromium, Mitochondria, Oxidative Stress, Tissues

\section{Introduction}

Potassium dichromate $\left(\mathrm{K}_{2} \mathrm{Cr}_{2} \mathrm{O}_{7}\right)$ is a chemical compound widely used in metallurgy, chrome plating, chemical industry, textile manufacture, wood preservation, photography and photoengraving, refractory and stainless steel industries and cooling systems [1]. The oxidation state and solubility of chromium $(\mathrm{Cr})$ compounds determine their toxicity. In contrast to $\mathrm{Cr}$ (III), which is a naturally occurring form and an essential trace element for humans and others mammals, $\mathrm{Cr}(\mathrm{VI})$ compounds are highly toxic [2]. Dolai et al. [3] have summarized the acute toxicity, chronic toxicity, neurotoxicity, reproductive toxicity, genotoxicity, carcinogenicity and environmental toxicity of chromium. Potassium dichromate is a hexavalent form of $\mathrm{Cr}$ and has been demonstrated to induce oxidative stress and carcinogenic in nature [4-6].

Mitochondria provide most of the cellular energy (ATP). A strong decrease in the ATP levels in cells exposed to $\mathrm{Cr}$ (VI) was detected in hamster fibroblasts [7], human gingival [8], and rat thymocytes [9]. This effect was closely correlated with the inhibition of cellular respiration in human and rat lymphocytes [8], as well as rat hepatocytes [10]. The 
inhibitory action of $\mathrm{Cr}$ (VI) on mitochondrial respiration was detected in isolated rat liver [10] mitochondria, and also in rat liver sub mitochondrial particles [11]. The mechanism by which $\mathrm{Cr}$ (VI) interferes with the mitochondrial bioenergetics was not clarified. It has been assigned to the oxidizing activity of $\mathrm{Cr}$ (VI), which shunts electrons from electron donors coupled to ATP production, and to the ability of $\mathrm{Cr}$ (III), derived from $\mathrm{Cr}$ (VI) reduction, to form stable complexes with ATP precursors and enzymes involved in the ATP synthesis [7, 12]. Reduction of Cr (VI) induced the generation of hydroxyl radical $(\mathrm{OH})$ via the Fentonmechanism [13]. It is known that daily oral low-dose administration of $\mathrm{Cr}$ (VI) to rat's results in enhanced lipid peroxidation in liver and brain mitochondria [14].

In this present investigation, we have evaluated the effects on chromium-induced oxidative damage in liver and lungs mitochondria.

\section{Materials and Methods}

\subsection{Maintenance and Treatment of Animals}

Male albino rats of the Wistar strain (80-100 g) were fed with a lab-prepared diet, as described elsewhere [15], with water ad libitum. Laboratory acclimatized rats were divided into two groups of almost equal average body weight. The animals of one group were injected intraperitoneally (i.p.) with $\mathrm{Cr}$ as $\mathrm{K}_{2} \mathrm{Cr}_{2} \mathrm{O}_{7}$ at a dose of $0.8 \mathrm{mg}$ per $100 \mathrm{~g}$ body weight per day $\left(20 \% \mathrm{LD}_{50}\right)$ for 28 days, as described earlier [15]. The animals of the remaining group received only the vehicle $(0.9 \% \mathrm{NaCl})$, served as control. The body weights of the animals were taken in each day of treatment schedule.

\subsection{Tissue Collection}

After the experimental period, overnight fasting rats were sacrificed by cervical dislocation. The liver and lungs were immediately dissected out of the body and weighed. The tissues were then quickly stored at $-20^{\circ} \mathrm{C}$.

\subsection{Homogenization of Tissues}

A weighted portion of different tissues was homogenized in an ice cold 0.2 M PBS ( $\mathrm{pH} 7.4$ ) using glass homogenizer. Homogenized tissues were used for biochemical assays.

\subsection{Isolation of Mitochondria}

Rat liver and lungs mitochondria were isolated from male albino rats by differential centrifugation according to conventional methods [16].

\subsection{Analytical Methods}

Lipid peroxidation was measured according to the method of Ohkawa et al. [17]. Malondialdehyde (MDA) was determined from the absorbance of the pink coloured product (TBARS) of thiobarbituric acid-MDA reaction, at $530 \mathrm{~mm}$. The reaction of MDA with TBA has been widely adopted as a sensitive method of lipid peroxidation in animal tissues.
Conjugated dienes was measured according to the method of Slater [18]. NO release assays were done in liver and lungs according to the method of Sanai et al. [19].

GSH (reduced glutathione) was measured according to the method of Griffith [20]. GSSG was also assayed after derivatization of GSH with 2 vinylpyridine. GSSG (oxidized glutathione) was measured by the method of Griffith [20].

Catalase activity was determined at room temperature by using a slightly modified version of Aebi, [21]. The molar extinction coefficient of $43.6 \mathrm{Mcm}-1$ was used to determine CAT activity. One unit of activity is equal to the millimoles of $\mathrm{H}_{2} \mathrm{O}_{2}$ degraded per minute per milligram of protein. SOD activity was estimated by measuring the percentage inhibition of the pyrogallol auto- oxidation by SOD according to the method Marklund \& Marklund [22].

The rate of oxidation of reduced glutathione (GSH) by $\mathrm{H}_{2} \mathrm{O}_{2}$ as catalyzed by the glutathione peroxidase (GSH-Px) is assayed for the measurement of enzyme activity. Glutathione peroxidase activity was measured according to method of Pagila and Valentine [23]. The activity of glutathione reductase was measured by the method of Miwa [24]. Glutathione S-transferase activity was also measured according to the method of Habig et al. [25].

Total protein of plasma and tissues was estimated according to the method of Lowry et al. [26].

\subsection{Statistical Analysis}

The data were expressed as mean \pm standard error. The significance in the differences between the means were evaluated by student's ' $t$ ' test, and probability levels of $5 \%$ or less were considered to be statistically significant.

\section{Results}

The level of MDA and conjugated dienes were increased significantly in liver and lungs mitochondria in chromium treated rats when compared with control group (Figure $1 \&$ 2). On the other hand, it was found that chromium treatment significantly increased NO production in liver and lungs mitochondria when compared with control group (Figure 3).

Figure 4 shows that the activity of SOD was significantly reduced in liver and lungs mitochondria after chromium treatment when it compared with control. On the other hand, the catalase activity of liver and lungs homogenate was significantly decreased when compared with control group (Figure 5).

The levels of GSH and GSSG were significantly diminished in liver and lungs mitochondria in response to chromium treatment (Figure 6 \& 7). The activities of GSHPx, GR and G-S-T were significantly decreased in response to chromium when compared with control in both liver and lungs mitochondria (Figure 8, $9 \& 10$ ).

\section{Discussion}

The mitochondrion appears to be an important cellular organelle playing a role in the metabolism of hexavalent 
chromium. $\mathrm{Cr}$ (VI) dramatically decreased oxygen consumption and NADH levels in isolated rat liver and heart mitochondria [11]. Intact mitochondria take up and reduced chromium (VI), producing chromium (V) species and the chromium (V) generated efficiently oxidized NADH [13]. Chromium (III), which does not penetrate into intact mitochondria, had no effect on the respiratory rats in sonicated mitochondria [9]. Chromium (VI) is a potent inhibitor of mitochondria, there enzymes ( $\alpha$-ketoglutarate dehydrogenase, pyruvate dehydrogenase and $\beta$-hydroxyl butarate dehydrogenase) may explain the observed inhibitory respiration in liver mitochondria and decreasing in cellular levels of ATP and GTP [9].

In our present study, the effective dose and duration of hexavalent chromium has been carried out against chromiuminduced toxicity in liver and lungs mitochondria. This study shows a significant increase the MDA and conjugated dienes levels in liver and lungs mitochondria in chromium induced rats (Figure $1 \&$ 2). Bagchi et al. [27] showed that chromium (VI) induces increases in hepatic mitochondrial and microsomal lipid peroxidation. These results may be due to oxidative damage in inner mitochondrial membrane may also be involved. The generation of ROS is another cause to increase the MDA level in liver and lungs mitochondria due to chromium induced toxicity. Large amounts of ROS generated can bring on injury to cellular proteins, lipids, and DNA leading to oxidative stress [28]. The observed increase in MDA and conjugated dienes is a good evidence for oxidative stress. The study also showed a significant increase in NO production in liver and lungs (Figure 3). The simultaneous production of superoxide and $\mathrm{NO}$ produces peroxinitrite $\left(\mathrm{ONOO}^{-}\right)$, a very strong oxidant and nitrating agent. The formation of NO in liver and lungs mitochondria may have an important consequence, because this compound binds to the heam group from cytochromes (in particularly, cytochrome oxidase) and inhibits respiration [29]. This may, in turn, stimulate $\mathrm{O}_{2}^{-}$ formation which may react with more NO, forming peroxinitrite, an oxidant capable of inhibiting important enzymes and affecting mitochondrial integrity $(30,31)$.

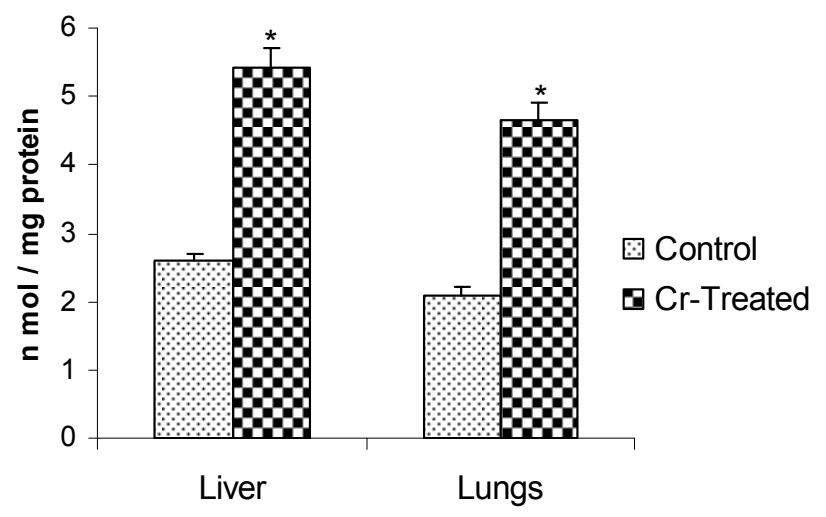

Figure 1. Changes the MDA content in liver and lungs mitochondria following exposure to chromium. Data represents mean $\pm S E, N=12$, * indicates significant difference $(P<0.05)$ compared to control.

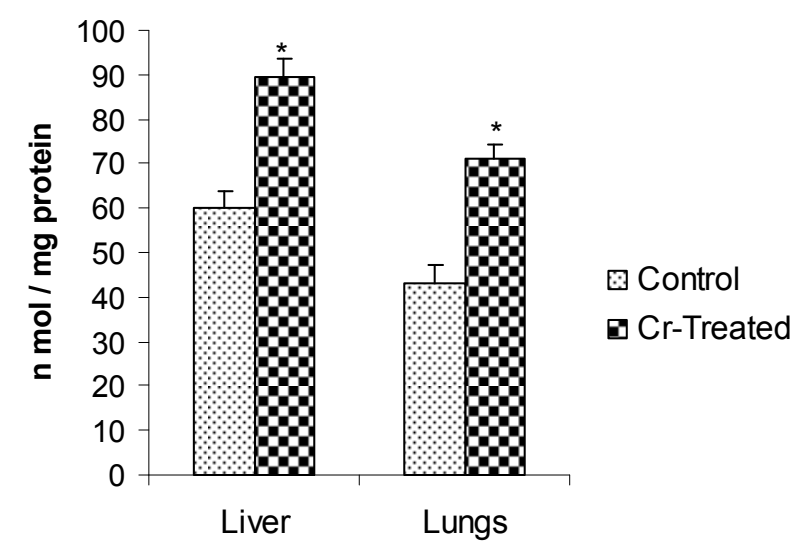

Figure 2. Changes the conjugated dienes content in liver and lungs mitochondria following exposure to chromium. Data represents mean $\pm S E$, $N=12$, * indicates significant difference $(P<0.05)$ compared to control.

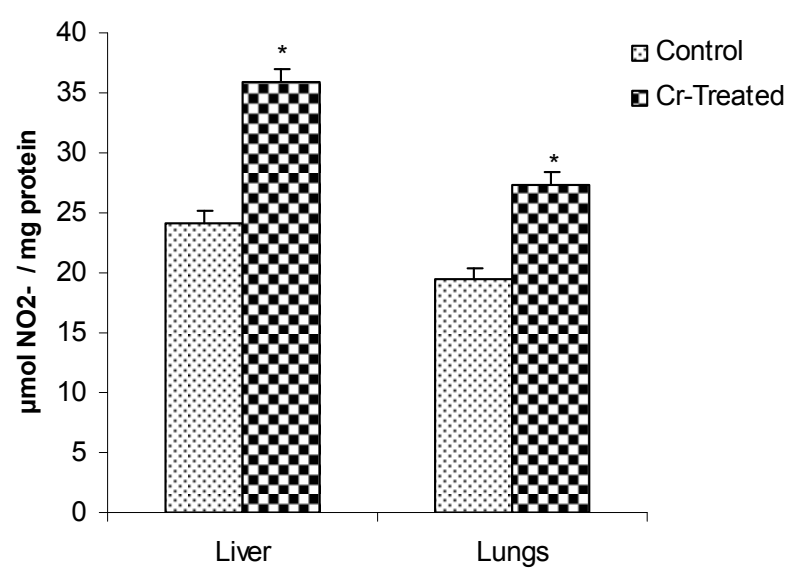

Figure 3. Changes the nitric oxide production (NO) in liver and lungs mitochondria following exposure to chromium. Data represents mean $\pm S E$, $N=12$, * indicates significant difference $(P<0.05)$ compared to control.

SOD is believed to play a major role in the first line of antioxidant defense by catalyzing the dismutations of super oxide anion radicals to form $\mathrm{H}_{2} \mathrm{O}_{2}$ and $\left[\mathrm{O}_{2}^{-}\right]$. In the present study, decreased SOD activity observed in chromium-induce group in liver and lungs mitochondria (Figure 4) could be explained by the massive production of super oxide anion. The production of such anions overrides enzymatic activity and leads to a fall in its concentration in tissues [32]. Pedraza-chaverri et al. [33] indicated that most of the antioxidant enzymes become inactive after potassium dichromate exposure either due to the direct binding of heavy metals to enzyme active site if it contains $\mathrm{SH}$ group or to the displacement of metal co-factors from active sites. The production of such anions leads to a fall in its concentration in liver and lungs mitochondria. Catalase (CAT), a major $\mathrm{H}_{2} \mathrm{O}_{2}$ detoxifying enzyme found in peroxisomes, is also present in heart mitochondria [34]. However, this enzyme has not been found in mitochondria from other tissue, including skeletal muscle [35]. We have measured CAT activity using liver and lungs homogenates (Figure 5). This suppressed activity of CAT may be due to the overproduction of $\mathrm{H}_{2} \mathrm{O}_{2}$ in the system during chromium treatment compared with the control group. 


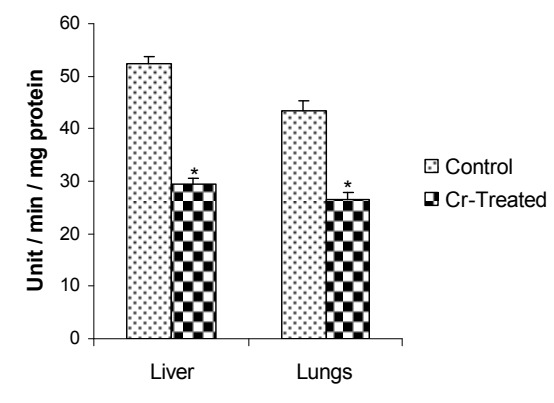

Figure 4. Changes the SOD activity in liver and lungs mitochondria following exposure to chromium. Data represents mean $\pm S E, N=12$, * indicates significant difference $(P<0.05)$ compared to control.

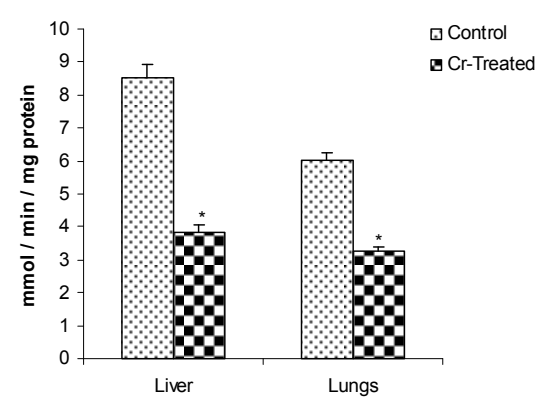

Figure 5. Changes the Catalase activity in liver and lungs homogenate following exposure to chromium. Data represents mean $\pm S E, N=12$, * indicates significant difference $(P<0.05)$ compared to control.

It has been known that lipid peroxidation occurs as a result of the decrease in intracellular reduced glutathione (GSH) concentration. Ueno et al. [36] reported that the content of intracellular GSH in isolated rat hepatocytes was diminished after chromium (VI) treatment. The levels of GSH and GSSG have significantly diminished in liver and lungs mitochondria (Figure $6 \& 7$ ). Glutathione is normally present in millimolar concentrations in cells and is known to protect the cellular system against the toxic effects of lipid peroxidation. It is very important in maintaining cellular redox status [37] and its depletion is considered as a marker of oxidative stress [38]. These results suggested that super oxide anion and $\mathrm{H}_{2} \mathrm{O}_{2}$ are main source of chromium induced free radicals depleting the cellular antioxidant.

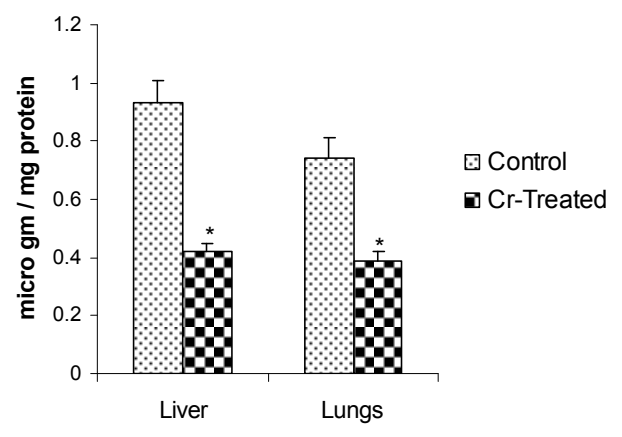

Figure 6. Changes the GSH level in liver and lungs mitochondria following exposure to chromium. Data represents mean $\pm S E, N=12$, * indicates significant difference $(P<0.05)$ compared to control.

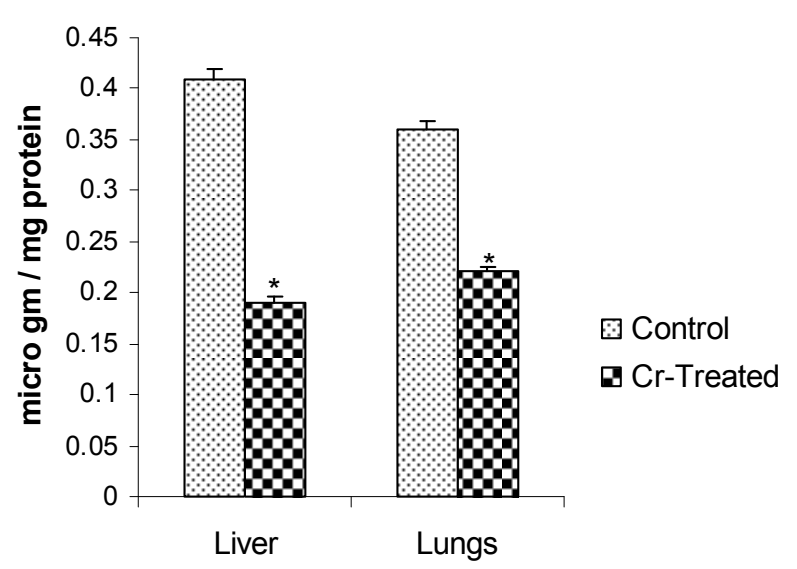

Figure 7. Changes the GSSG level in liver and lungs mitochondria following exposure to chromium. Data represents mean $\pm S E, N=12$, * indicates significant difference $(P<0.05)$ compared to control.

$\mathrm{GP}_{\mathrm{X}}$ is considered to biologically essential in the reduction of $\mathrm{H}_{2} \mathrm{O}_{2}$. The decline in the activity of $\mathrm{GP}_{\mathrm{X}}$ in chromium induce rats in our study (Figure 8) may be due to the intracellular accumulation of ROS with subsequent development of liver and lungs injury. Glutathione reductase (GR) is one of the most important enzymes detoxifying against oxidative stress because GR is considered biologically essential in reduction of oxidized glutathione to reduced glutathione. In our present study, the activity of GR in liver and lungs mitochondria declined in chromiuminduces rats (Figure 9). This might have been triggered by low levels of NADPH, which is a cofactor of GR to convert GSSG to GSH. Glutathione- S- transferase (GST) is an enzyme that utilizes glutathione in reaction contributing to the transformation of a wide range of components including carcinogens, therapeutic drugs and products of oxidative stress. The decreased in the activity of GST in chromium induced rat liver and lungs mitochondria (Figure 10) might be due to increased oxidative stress as these enzymes tend to deplete in the presence of ROS.

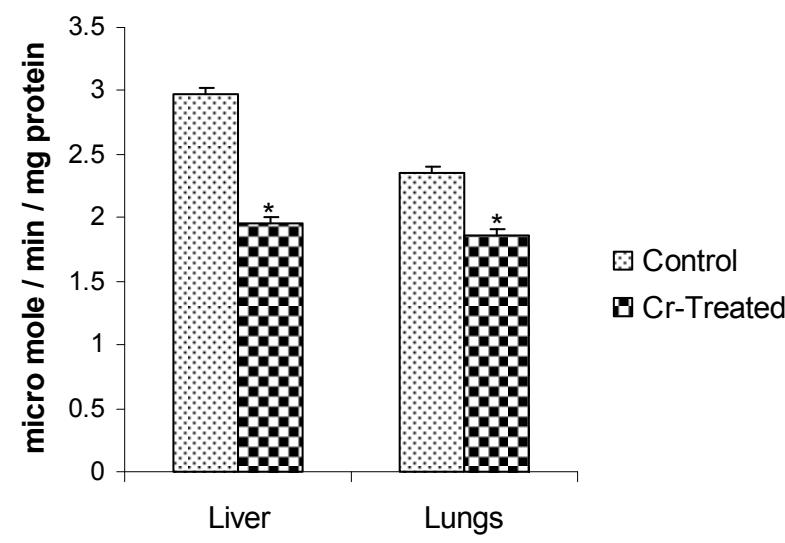

Figure 8. Changes the activity of GPx in liver and lungs mitochondria following exposure to chromium. Data represents mean $\pm S E, N=12$, * indicates significant difference $(P<0.05)$ compared to control. 


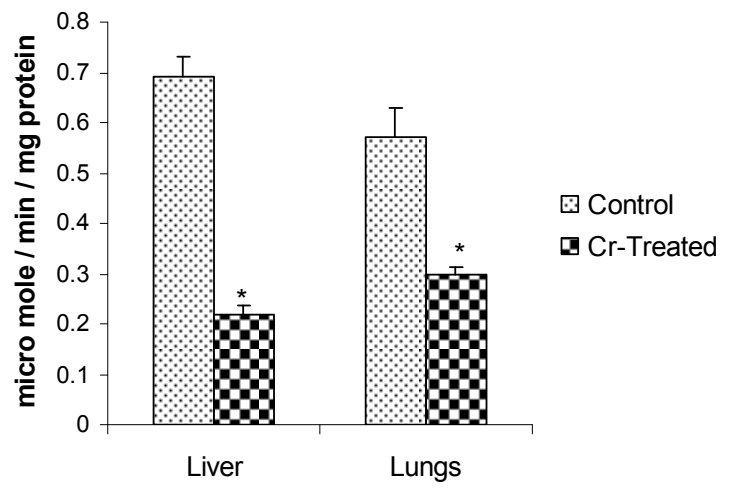

Figure 9. Changes the activity of GR in liver and lungs mitochondria following exposure to chromium. Data represents mean $\pm S E, N=12$, * indicates significant difference $(P<0.05)$ compared to control.

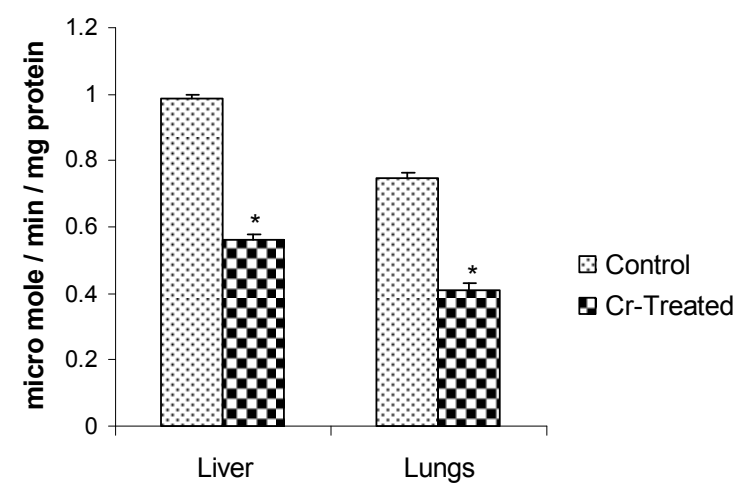

Figure 10. Changes the activity of GST in liver and lungs mitochondria following exposure to chromium. Data represents mean $\pm S E, N=12$, * indicates significant difference $(P<0.05)$ compared to control.

\section{Conclusion}

From the above study it may be concluded that $\mathrm{Cr}$ treatment at the present dose and duration induces oxidative stress due to the generation of reactive oxygen species (ROS) in liver and lungs mitochondria. However, further studies are required to elucidate the exact mechanism underlying $\mathrm{Cr}$ induced oxidative damage.

\section{References}

[1] Barceloux, D (1999). Chromium. Clin. Toxicol., 37:173-194.

[2] Wang, X. F.; Xing, M. L.; Shen, Y.; Zhu, X. and Xu, L. H. (2006). Oral administration of $\mathrm{Cr}$ (VI) induced oxidative stress, DNA damage and apoptotic cell death in mice. Toxicology, 228: $16-23$.

[3] Dolai, D.; Tripathy, S.; Dey, S. K. and Roy, S. (2016). Review on health effects of chromium exposure: reflection from oxidative stress towards carcinogenicity. Int. J. Pharm. Bio. Sci., 7(3): (B) 343-354.

[4] Stohs, S. J. and Bagchi, D. (1995). Oxidative mechanisms in the toxicity of metal ions. Free Radical Biol. Med., 18 (2):321-336.
[5] Bagchi, D.; Balmoori, J.; Bagchi, M.; Ye, X.; Williams, C. B. and Stohs, S. J. (2002a). Comparative effects of TCDD, endrin, naphthalene and chromium VI on oxidative stress and tissue damage in the liver and brain tissues of mice. Toxicology, 175: 73-82.

[6] Bagchi, D.; Stohs, S. J.; Downs, B. W.; Bagchi, M. and Preuss, H. (2002b). Cytotoxicity and oxidative mechanisms of different forms of chromium. Toxicol., 180: 5-22.

[7] Debetto, P.; Dal Toso, R.; Varotto, R.; Bianchi, V. and Luciani, S. (1982). Effects of potassium dichromate on ATP content of mammalian cells cultured in vitro. Chem. Biol. Interact., 41(1): 15-24.

[8] Messer, R. L. and Lucas, L. C. (2000). Cytotoxicity of nickelchromium alloys: Bulk alloys compared to multiple ion salt solutions. Dent. Mater., 16: 207-212.

[9] Lazzarini, A.; Luciani, S.; Beltrami, M. and Arslan, P. (1985). Effects of Chromium (VI) and Chromium (III) on energy Charge and oxygen consumption in Rat thermosytes. Chem. Biol. Interact., 53(3): 273-281.

[10] Ryberg, D. and Alexander, J. (1984). Inhibitory action of hexavalent chromium ( $\mathrm{Cr}$ (VI)) on the mitochondrial respiration and a possible coupling to the reduction of $\mathrm{Cr}(\mathrm{VI})$. Biochem. Pharmacol., 33: 2461-2466.

[11] Ryberg, D. and Alexandar, A. (1990). Mechanism of Chromium toxicity in mitochondria.. Chem. Biol. Interact., 75(2):141-151.

[12] Bianchi, V.; Debetto, P.; Zantedeschi, A. and Levis, A. G. (1982). Effects of hexavalent chromium on the adenylate pool of hamster fibroblasts. Toxicology., 25(1):19-30.

[13] Shi, X.; Dalal, N. S. and Vallyathan, V. (1991). One-electron reduction of carcinogen chromate by microsomes, mitochondria, and Escherichia coli: Identification of $\mathrm{Cr}(\mathrm{V})$ and OH radical. Arch. Biochem. Biophys., 290(2): 381-386.

[14] Travacio, M.; María Polo, J. and Llesuy, S. (2000). Chromium (VI) induces oxidative stress in the mouse brain. Chromium (VI) induces oxidative stress in the mouse brain. Toxicology, 150(1-3):137-146.

[15] Dey, S. K.; Nayak, P. and Roy, S. (2003). Alpha-tocopherol supplementation on chromium toxicity: a study on rat liver and kidney cell membrane. J. Environ. Sci., 15: 356-359.

[16] Gazotti, P.; Malmstron, K. and Crompton, M. A. (1979). Laboratory manual on transport and bioenergetics. In: Carofoli E, Semanza G, editors. Membrane Biochemistry. New York: Springer-Verlag, 62-69.

[17] Ohkawa. H,; Ohisi, N. and Yagi, K. (1979). Assay for lipid peroxides in animal tissues by thiobarbituric acid reaction. Anal. Biochem., 95: 351-358.

[18] Slater, T. I. (1980). Overview of methods used for detecting lipid peroxidation. Methods Enzymol., 105: 283-293.

[19] Sanai, S.; Tomisato, M.; Shinsuka, N.; Mayoko, Y.; Mayoko, H. and Akio, N. (1998). Protective role of nitric oxide in S. aurues infection in mice. Infect. Immun. 66: 1017-1028. PMID: 9488390.

[20] Griffith, O. W. (1980). Determination of glutathione and glutathione sulfide using glutathione reductase and 2-vinyl pyridine. Anal. Biochem., 106: 207-212. 
[21] Aebi, H. (1984). Catalase in vitro. Methods Enzymol, 105: $121-126$.

[22] Marklund, S. and Marklund, G. (1974). Involvement of superoxide anion radical in autoxidation of pyrogallol and a convenient assay of superoxide dismutase. Eur. J. Biochem., 47: 469-474.

[23] Paglia, D. E. and Valentine, W. N. (1967). Studies on quantitative and qualitative characterization of erythrocyte glutathione peroxidase. J. Lab. Clin. Med., 70: 158-169.

[24] Miwa, S. (1972). Hematology, In: Modern Medical Techonology, 3: 306-310.

[25] Habig, W. H.; Pabst, M. J. and Jakoby, W. B. (1974). Glutathone S-transferases, the first enzymatic step in mercapturic acid formation. J. Biol. Chem., 249: 7130-7139.

[26] Lowry, O. H.; Roseborough, N. J.; Farr, A. L. and Randll, A. J. (1951). Protein measurement with Folin's phenol reagent. J. Biol. Chem., 193: 265-275.

[27] Bagchi, D.; Hossoun, E. A.; Bagchi, M. and Stohs, S. J. (1995). Chromium-induced excretion of urinary lipid metabolites, DNA damage, nitric oxide production and generation of reactive oxygen species in Sprague-Dawley rats. Comp. Biochem. Physiol. C Pharmacol. Toxicol. Endocrinol, 110(2): 177-187.

[28] Nordbeg, J. and Arner, E. S. (2001). Reactive oxygen species, antioxidants, and the mammalian thioredoxin system. Free Radical Biol. Med., 31: 1287-1312.

[29] Poderoso, J. J.; Carreras, M. C.; Lisdero, C.; Riobo, N.; Schopfer, F. and Boveris, A. (1996). Nitric oxide inhibits electron transfer and increases superoxide radical production in rat heart mitochondria and submitochondrial particles. Arch. Biochem. Biophys., 328: 85-92.
[30] Cassina, A. and Radi, R. (1996). Differential inhibitory action of nitric oxide and peroxynitrite on mitochondrial electron transport. Arch. Biochem. Biophys., 328: 309-316.

[31] Radi, R.; Cassina, A. and Hodara, R. (2002). Nitric oxide and peroxynitrite interactions with mitochondria. Biol. Chem., 383: 401-409.

[32] Srinivasan, K.; Narayanan, S.; Ananthasadagopan, S. and Ganapasam, S. (2008). Chromium (VI)-induced oxidative stress and apoptosis is reduced by garlic and its derivative Sallylcysteine through the activation of Nrf2 in the hepatocytes of Wistar rats. J. Appl. Toxicol., 28:908-919.

[33] Pedraza-Chaverri, J.; Barrera, D.; Medina-Campos, O.N.; Carvajal, R.C.; Hernandez-Pando, R.; Macias-Ruvalcaba, N.A. et al. (2005). Time course study of oxidative and nitrosative stress and antioxidant enzymes in $\mathrm{K}_{2} \mathrm{Cr}_{2} \mathrm{O}_{7}$-induced nephrotoxicity. BMC Nephrol., 26: 6-14.

[34] Radi, R.; Turrens, J. F.; Chang, I. Y.; Bush. K. M.; Crapo, J. D. and Freeman, B. A. (1991). Detection of catalase in rat heart mitochondria. J. Biol. Chem., 266: 22028-22034.

[35] Phung, C. D.; Ezieme, J. A. and Turrens, J. F. (1994). Hydrogen peroxide metabolism in skeletal muscle mitochondria. Arch. Biochem. Biophys., 315: 479-482.

[36] Ueno, S.; Susa, N.; Furukawa, Y.; Aikawa, K.; Itagaki, I.; Komiyama, T. and Takashima, Y. (1988). Effect of chromium on lipid peroxidation in isolated rat hepatocytes, Japanese Journal of Veterinary Science, 50: 45-52.

[37] Rao, A. V. and Shaha, C. (2001). Multiple glutathione Stransferase isoforms are present on male germ cell plasma membrane. FEBS Lett., 507:174-180.

[38] Lu, S. C. (1999). Regulation of hepatic glutathione synthesis: current concepts and controversies. FASEB J., 13: 1169-1183. 